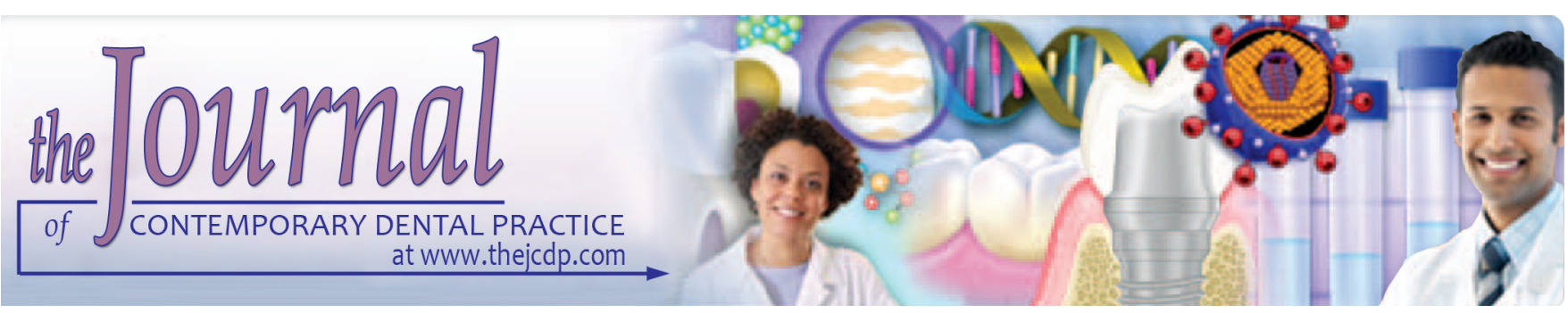

\title{
Cariogenic Potential of the commonly Prescribed Pediatric Liquid Medicaments in Kingdom of Saudi Arabia: An in vitro Study
}

${ }^{1}$ Megha Gupta, ${ }^{2}$ Suman Panda

\section{ABSTRACT}

Aim: The aim of this study was to assess the cariogenic potential of the commonly prescribed pediatric liquid medicaments (PLMs) for dental disease in Jazan region, Kingdom of Saudi Arabia.

Materials and methods: Seven most commonly prescribed PLMs were selected by prior questioning the pediatric dentists as well as general dentists in Jazan region. The endogenous $\mathrm{pH}$ and sucrose concentrations of the liquid medicaments were assessed. The endogenous $\mathrm{pH}$ was assessed by Hanna $\mathrm{pH}$ meter instrument. The sucrose concentration was assessed by anthrone reagent method.

Results: All the PLM were acidic. The $\mathrm{pH}$ of the PLM ranged from 4.22 to 6.10 . All the PLM contained sucrose and its concentration ranged from 5.38 to $11.41 \mathrm{gm} \%$ in the samples.

Conclusion: In this study, all the PLM were acidic and contained sucrose. Hence, they have cariogenic potential.

Clinical significance: Parents and dentists are unaware of the hidden sugars and cariogenicity of these medications. Strict oral hygiene instructions are mandatory for the children taking these medications. The use of PLM should also be minimized and parents should seek early dental treatment to restore child's oral health.

Keywords: Cariogenicity, Pediatric liquid medicaments, $\mathrm{pH}$, Sucrose.

How to cite this article: Gupta M, Panda S. Cariogenic Potential of the commonly Prescribed Pediatric Liquid Medicaments in Kingdom of Saudi Arabia: An in vitro Study. J Contemp Dent Pract 2017;18(4):307-311.

Source of support: Nil

Conflict of interest: None

\footnotetext{
1,2 Department of Preventive Dental Sciences, Division of Pedodontics, College of Dentistry, Jazan University, Jazan Kingdom of Saudi Arabia

Corresponding Author: Megha Gupta, Department of Preventive Dental Sciences, Division of Pedodontics, College of Dentistry Jazan University, Jazan, Kingdom of Saudi Arabia, Phone: +00966536856649, e-mail: meghaaguptaa@yahoo.com
}

\section{INTRODUCTION}

Liquid medications are generally prescribed to the pediatric population for the commonly occurring ailments. They are widely available and easily accepted by both parents and children. Since it is difficult for children to swallow the tablets/capsules at a younger age, liquid medicament should be an easy way to administer the drugs to the children.

The majority of the pediatric liquid medicaments (PLMs) are made palatable by adding sugars to it. ${ }^{1}$ This would mask the taste of its unpleasant active ingredient and hence, help to gain the child's compliance..$^{2-4}$ Sucrose is the commonly adjoined sweetener for such medicated formulations as it is an easily processed substance, costeffective, and nonhygroscopic. ${ }^{5}$ Fructose and glucose are also added to the PLM. ${ }^{4}$ These added sugars may be fermented by oral bacteria leading to the acid formation and a drop in the intraoral $\mathrm{pH}$. Pediatric liquid medicaments also contain certain acids, which are added as buffering agents to maintain chemical stability, control tonicity, and physiological compatibility of the solution. They also improve the flavor and hence, the medication becomes more acceptable to children. ${ }^{6}$

The added sugars along with the acidic solutions may produce unwanted dental side effects in children. Hence, a high intake of oral medications may result in reduced hardness of primary teeth, ${ }^{7}$ morphological enamel alteration, ${ }^{8}$ dentinal hypersensitivity, ${ }^{9}$ and increased prevalence of dental caries. ${ }^{10}$ Many of the authors have expressed their concerns that oral liquid medications contribute to the total sugar load and to the development of dental caries in children. ${ }^{11-13}$

However, in the Middle Eastern countries (especially Kingdom of Saudi Arabia), there have been no studies reported about the cariogenic potential of the commonly prescribed PLM to children. Since the PLM are routinely dispensed at the various hospitals and primary health 
care centers in Kingdom of Saudi Arabia, it is very important for us to assess their cariogenic potential. Hence, this study was carried out to evaluate the cariogenic potential of the most commonly prescribed PLM in Jazan region, Kingdom of Saudi Arabia.

\section{MATERIALS AND METHODS}

Seven most commonly prescribed PLMs for oral diseases were selected for the study (Table 1). This selection was done after consulting the general dentists as well as the pediatric dentists working in various government and private sectors in Jazan region, Kingdom of Saudi Arabia. These medicaments were from different pharmaceutical companies. These medicaments included antibiotics, analgesics, and a multivitamin. All the samples were coded as RSE1 to RSE 7.

Objectives of the study are as follows:

- To determine the endogenous pH of the seven PLMs

- To assess the concentration of sucrose in these drugs.

\section{Endogenous pH Estimation}

The endogenous $\mathrm{pH}$ was measured using HANNA digital $\mathrm{pH}$ meter (Fig. 1). The $\mathrm{pH}$ meter was set to $\mathrm{pH}$ mode and the temperature was adjusted to $25^{\circ} \mathrm{C}$. The electrode was placed in the sample to be tested. The $\mathrm{pH}$ of the solution appeared in the display. The display was allowed to be stabilized before the reading was taken. The $\mathrm{pH}$ electrode was rinsed and placed back in the storage solution.

\section{Endogenous Sucrose Assessment}

The sucrose estimation in the sample was done by anthrone reagent method. The anthrone method is an example of a colorimetric method of determining the concentration of the total sugars in a sample. It is nonstoichiometric, and therefore, it is necessary to prepare a calibration curve using a series of standards of known carbohydrate concentration (Graph 1). All the experiments were done in triplicates (Figs 2A and B). Sugars reacted with the anthrone reagent under acidic conditions to yield a blue - green color. The sample was mixed with sulfuric acid and the anthrone reagent, and then boiled until the reaction was completed (Figs 3A and B). The solution was then allowed to cool and

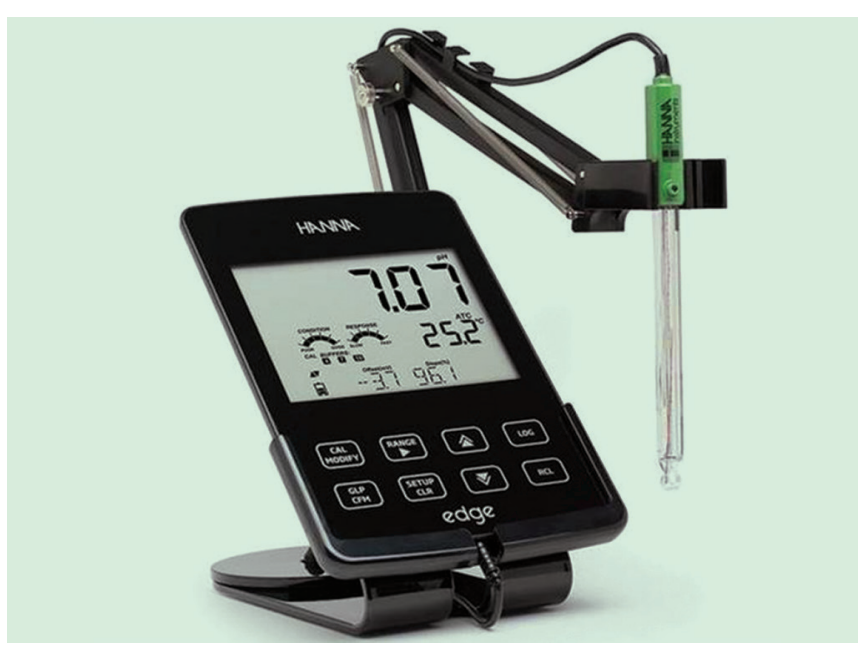

Fig. 1: Hanna digital $\mathrm{pH}$ meter

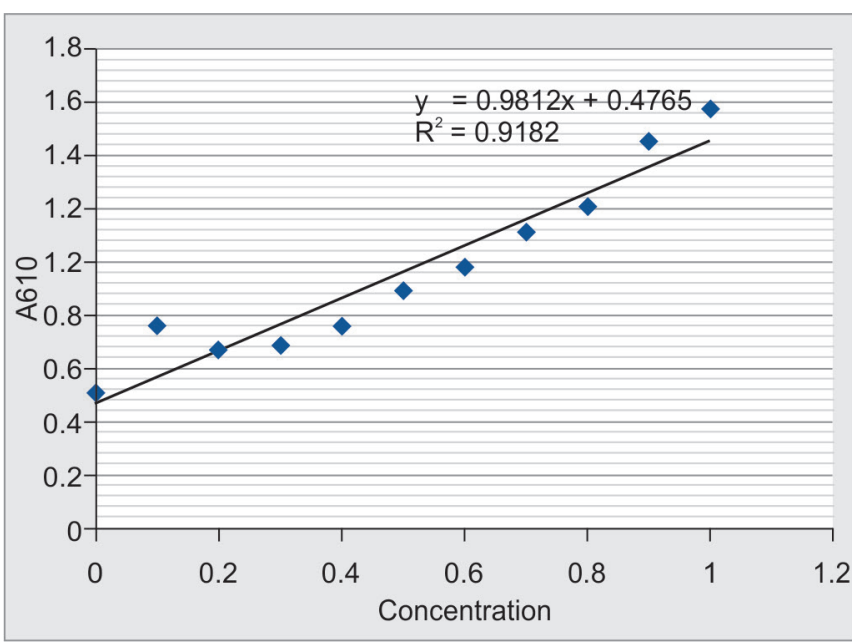

Graph 1: Standard graph for sucrose

its absorbance was measured at $620 \mathrm{~nm}$. There was a linear relationship between the absorbance and the amount of sugar that was present in the original sample. This method determines both reducing and nonreducing sugars because of the presence of the strongly oxidizing sulfuric acid.

$$
\text { Percentage total apparent sucrose }=\frac{A_{\text {sample }}}{A_{\text {standard }}} \times 15
$$

\section{RESULTS}

The $\mathrm{pH}$ measurements in the provided samples are given in Table 2. It ranged from 4.22 for the nutritional supplement

Table 1: Pediatric Liquid Medicaments selected for the study

\begin{tabular}{|c|c|c|c|}
\hline PLM & Generic name & Trade name & Code \\
\hline Analgesic, antipyretic & Paracetamol & Adol & RSE 1 \\
\hline Non-steroidal anti-inflammatory drug & Ibubrufen & Medafen & RSE 2 \\
\hline Antibiotic & Amoxicillin trihydrate & Julphamox & RSE 3 \\
\hline Antibiotic & Amoxicillin trihydrate & Megamox & RSE 4 \\
\hline Antibiotic & Metronidazole benzoate & Riazole & RSE 5 \\
\hline Antibiotic & Amoxicillin and Potassium Clavulanate & Julmentin & RSE 6 \\
\hline Nutritional supplement & Multivitamin & Life mark & RSE 7 \\
\hline
\end{tabular}



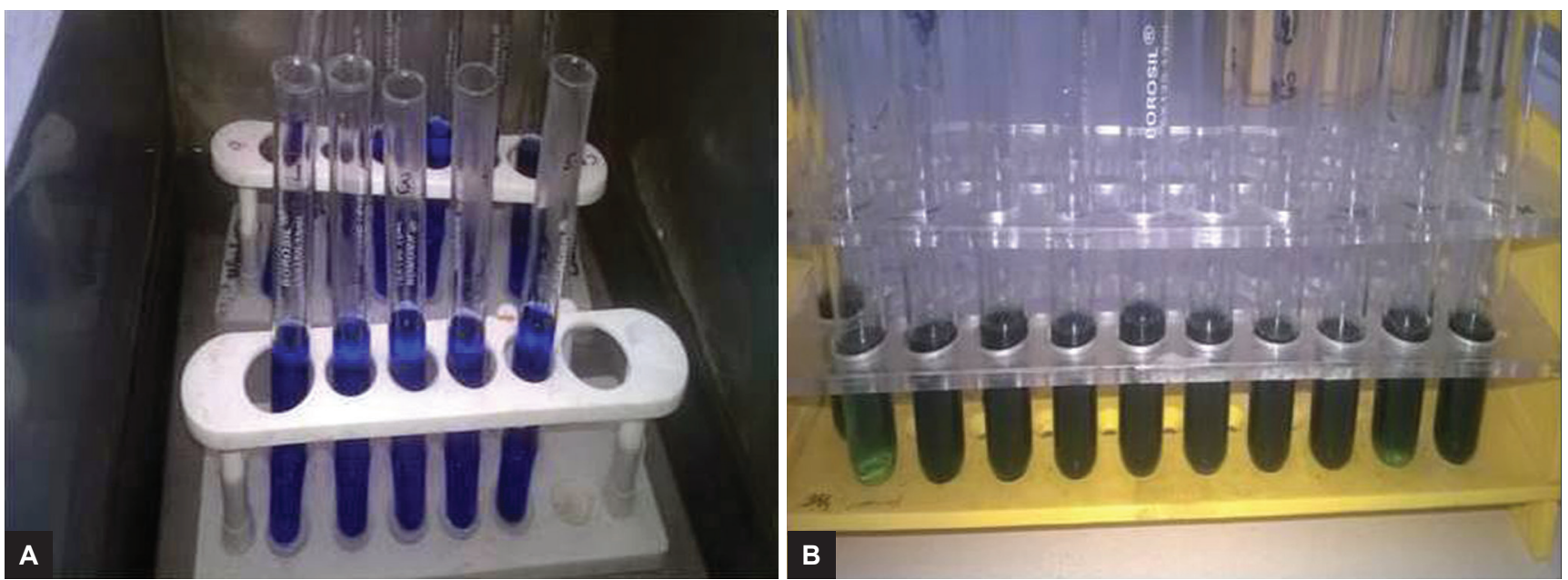

Figs 2A and B: Sucrose standard preparation. (A) Fehling solution added in sucrose solution; and (B) addition of anthrone reagent after Fehling treatment

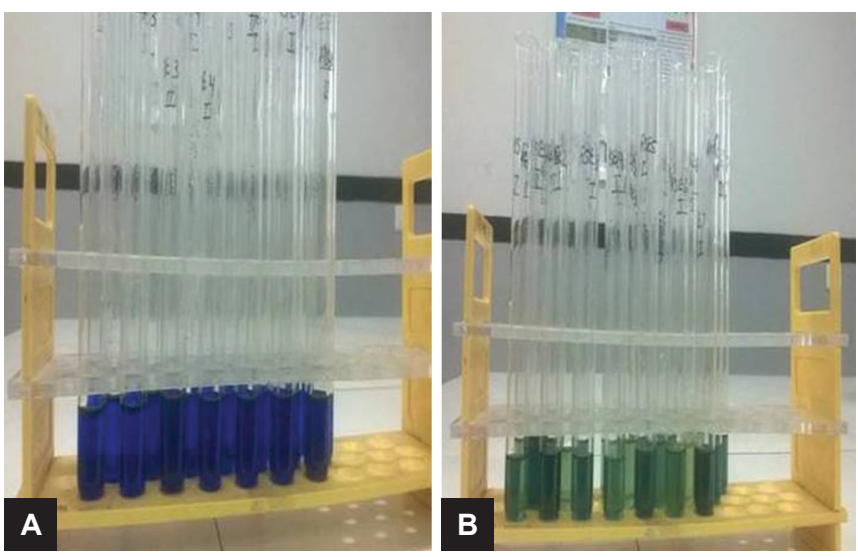

Figs $3 A$ and $B$ : Assessment of sucrose in the study samples. (A) Study samples after treated with Fehling solution; and (B) study samples after being treated with anthrone

"Life mark" to 6.10 for antibiotic "Julphamox." Hence, all the drugs were acidic.

Sucrose was present in all the samples. The concentration of sucrose in each sample is given in Table 3. Nonsteroidal anti-inflammatory drug "Medafen" contained the highest amount of sucrose, which was $11.41 \mathrm{gm} \%$.

\section{DISCUSSION}

Dental caries is the most chronic disease seen in children and is a major concern worldwide. ${ }^{14,15}$ It is a disease of the calcified tissues of the teeth caused by the action of microorganisms on fermentable carbohydrates. Sugars are known to be the principal etiologic agent for dental caries. Sucrose is considered to be the arch criminal and the major etiologic agent for dental caries. ${ }^{16}$ Many parents are aware that sugar causes tooth decay, but commonly relate this solely with the consumption of sweets and biscuits. They are often unaware of the hidden, added sugar in many foods and drinks, including pediatric liquid
Table 2: $\mathrm{pH}$ of the Pediatric Liquid Medicaments

\begin{tabular}{lll}
\hline SI. no. & Sample code & $\mathrm{pH}$ \\
\hline 1 & RSE 1 & 5.78 \\
2 & RSE 2 & 5.66 \\
3 & RSE 3 & 6.10 \\
4 & RSE 4 & 4.87 \\
5 & RSE 5 & 5.69 \\
6 & RSE 6 & 5.39 \\
7 & RSE 7 & 4.22 \\
\hline
\end{tabular}

Table 3: Sucrose concentration in the different samples as determined by Anthrone method

\begin{tabular}{|c|c|c|c|c|}
\hline $\begin{array}{l}\text { SI. } \\
\text { no. }\end{array}$ & $\begin{array}{l}\text { Sample } \\
\text { code }\end{array}$ & $\begin{array}{l}\text { Raw value in } \\
\text { triplicates }\end{array}$ & $\begin{array}{l}\text { Mean } \pm \\
\text { Standard } \\
\text { deviation }\end{array}$ & $\begin{array}{l}\text { Percent } \\
\text { total } \\
\text { apparent } \\
\text { sucrose } \\
\text { (gm\%) }\end{array}$ \\
\hline 1 & Standard & $1.938,1.838,1.765$ & $1.847 \pm 0.0868$ & - \\
\hline 2 & RSE 1 & $0.276,0.255,0.110$ & $0.68 \pm 0.09$ & 5.56 \\
\hline 3 & RSE 2 & $0.643,1.438,0.761$ & $1.41 \pm 0.42$ & 11.41 \\
\hline 4 & RSE 3 & $0.193,0.601,0.585$ & $0.93 \pm 0.23$ & 7.53 \\
\hline 5 & RSE 4 & $0.334,0.217,0.221$ & $0.73 \pm 0.07$ & 5.92 \\
\hline 6 & RSE 5 & $0.941,0.888,0.832$ & $1.35 \pm 0.05$ & 10.93 \\
\hline 7 & RSE 6 & $0.262,0.167,0.141$ & $0.66 \pm 0.06$ & 5.38 \\
\hline 8 & RSE 7 & $0.858,0.980,0.997$ & $1.4 \pm 0.07$ & 11.4 \\
\hline
\end{tabular}

medicines. Not only the parents but also the health care workers are unaware of the hidden sugars in PLM, which can drastically predispose an individual to an increased susceptibility for dental caries.

The most conclusive evidence about the cariogenicity of liquid oral medicaments was provided by Roberts and Roberts ${ }^{17}$ and Feigal et $\mathrm{al}^{18}$ who showed that a continuous administration of sucrose-based medicines causes dental caries and related gingivitis. Various other studies have also confirmed that these preparations are cariogenic and acidogenic in nature. ${ }^{10-13}$ Thus, this study was conducted to investigate the cariogenic potential of 
the commonly used PLMs in Jazan region, Kingdom of Saudi Arabia.

The cariogenic potential of these medicaments depends on many factors, such as $\mathrm{pH}$, titratable acidity, sugar content, viscosity, frequency of ingestion, and physical and chemical properties affecting adherence to the enamel surface. ${ }^{19}$ In our study, we focused only on the inherent characteristics that cause dental caries. Hence, the most important factors responsible for cariogenicity, i.e., endogenous $\mathrm{pH}$ and sucrose concentration, were assessed.

Many liquid medications have an endogenous low $\mathrm{pH}^{20}$ that may itself contribute to demineralization or at least inhibit the demineralization-remineralization process in the newly erupted teeth. ${ }^{21}$ The sucrose metabolized by oral bacteria to acid end-products decreases the $\mathrm{pH}$. Low $\mathrm{pH}$ near the tooth surface causes ionic dissolution from the hydroxyapatite crystals and eventually carious lesions. In an in vivo study, it was concluded that PLM causes a drop in plaque $\mathrm{pH}$ sufficient to cause decalcification within 2 to 10 minutes, following its initial exposure to the teeth. ${ }^{12}$ Furthermore, high concentrations of fermentable carbohydrates in PLM may facilitate the growth of Streptococcus mutans by rapidly metabolizing sugars to acids; thus, initiating enamel demineralization.

The HANNA digital $\mathrm{pH}$ meter used in our study is more accurate and efficient than conventional electrode $\mathrm{pH}_{\text {meter. }}{ }^{12,22}$ In our study, three out of seven PLM had $\mathrm{pH}$ below the critical $\mathrm{pH}$ (5.5) of the oral cavity. The range was from 4.22 to 6.10 showing that all were acidic. This is in accordance with other studies. ${ }^{11-13,23}$

Different studies have concluded that the amount of sucrose in the PLM ranged from 0 to $67 \mathrm{gm} \%{ }^{24}$ All the PLM in our study contained sucrose, and it ranged from 5.38 to $11.41 \mathrm{gm} \%$. However, this is less compared with that reported in the other studies. Neves et $\mathrm{al}^{13}$ concluded that 10 out of 23 PLMs had sucrose in their study and the concentration ranged from 11.36 to $85.99 \mathrm{gm} \%$. Pomarico et $\mathrm{al}^{22}$ reported the presence of sucrose in 7 of the 10 samples studied, ranging between 5 and $54 \mathrm{gm} \%$.

Primary teeth are less mineralized than the permanent teeth. The primary enamel surface being less mature is more prone to dental caries. ${ }^{25}$ The oral clearance process is less effective in children than in adults due to lower salivary flow and less pronounced oral muscular coordination ability. ${ }^{26}$

Most of the syrups are given in divided doses of two to three to children. The night dose, especially, has a deleterious effect on the enamel as the salivary flow rate is diminished at night. ${ }^{26}$ Further, the pain from irreversible pulpitis is more at night while sleeping (posture) as there are high chances that children wake up from pain at night. To calm them, the analgesic syrup will be given at night. The last dose of an antibiotic is also given at night. These acidic and sucrose-containing syrups taken at nighttime, when there is decreased salivary clearance, can definitely increase the incidence of dental caries. In a child who is already suffering from dental caries, it will increase the severity of the disease. Though there are a good infrastructure and health care facilities, there are many reasons for the delay in seeking dental treatment in children in Jazan region. The lack of cooperation from the child, unwillingness to miss the school, lack of interest by the general dentist in providing dental treatment to young precooperative children, and ignorance of dental disease by the parents are the few reasons. In all such cases, PLMs are given to children to allay them from pain and discomfort. The increase of prescribed medicine intake and of self-medication in developed countries exposes a growing number of children to medication caries, which can be considered a public health problem. ${ }^{5}$

The patients, as well as dentists, should be aware of the hidden sugars in the medicines. In this study, all the PLM were acidic and contained sucrose. It is recommended that all sugar-containing medicines should be labeled with the concentration of sucrose present in them. An important method of preventing dental caries is patient education through reinforcement of good oral hygiene methods.

\section{CONCLUSION}

Pharmaceutical preparations with acidic $\mathrm{pH}$ and high sugar content have a potential of increasing the susceptibility to dental caries when used frequently.

All the PLMs in our study were found to be acidic. Nutritional supplement "Lifemark" was the most acidic of the PLM, followed by antibiotic "Megamox" (Amoxicillin).

All the PLMs had sucrose, but the concentration was less compared with other studies.

The dentists should be aware of the high cariogenic potential of the commonly prescribed liquid medicaments. The dental personnel should advise the mothers and caretakers to introduce oral hygiene practices after the consumption of the medications.

\section{ACKNOWLEDGMENT}

Authors would like to thank B. Lal Institute of Biotechnology, Jaipur, India, for granting permission to carry out this study at their institute.

\section{REFERENCES}

1. Neves BG, Pierro VS, Maia LC. Pediatricians' perceptions of the use of sweetened medications related to oral health. J Clin Pediatr Dent 2008 Winter;32(2):133-137.

2. Bradley M, Kinirons $M$. A survey of factors influencing the prescribing of sugar-free medicines for children by a group of general medical practitioners in Northern Ireland. Int J Paediatr Dent 1996 Dec;6(4):261-264. 
3. Nunn JH, Ng SK, Sharkey I, Coulthard M. The dental implications of chronic use of acidic medicines in medically compromised children. Pharm World Sci 2001 Jun;23(3):118-119.

4. Pierro VS, Abdelnur JP, Maia LC, Trugo LC. Free sugar concentration and $\mathrm{pH}$ of paediatric medicines in Brazil. Community Dent Health 2005 Sep;22(3):180-183.

5. Bigeard L. The role of medication and sugars in pediatric dental patients. Dent Clin North Am 2000 Jul;44(3):443-456.

6. Maguire A, Baqir W, Nunn JH. Are sugars-free medicines more erosive than sugars-containing medicines? An in vitro study of paediatric medicines with prolonged oral clearance used regularly and long-term by children. Int J Paediatr Dent 2007 Jul;17(4):231-238.

7. Costa CC, Almeida IC, Costa Filho LC. Erosive effect of an antihistamine-containing syrup on primary enamel and its reduction by fluoride dentifrice. Int J Paediatr Dent 2006 May;16(3):174-180.

8. Babu KL, Rai K, Hedge AM. Pediatric liquid medicaments - do they erode the teeth surface? An in vitro study: part I. J Clin Pediatr Dent 2008 Spring;32(3):189-194.

9. Bamise CT, Olusile AO, Oginni AO. An analysis of the etiological and predisposing factors related to dentin hypersensitivity. J Contemp Dent Pract 2008 Jul;9(5):52-59.

10. Mackie IC, Hobson P. Factors affecting the availability of sugar-free medicines for children - a survey in the UK. Int J Paediatr Dent 1993 Sep;3(3):163-167.

11. Nankar M, Walimbe H, Ahmed Bijle MN, Kontham U, Kamath A, Muchandi S. Comparative evaluation of cariogenic and erosive potential of commonly prescribed pediatric liquid medicaments: an in vitro study. J Contemp Dent Pract 2014 Jan;15(1):20-25.

12. Sunitha S, Prashanth GM, Shanmukhappa, Chandu GN, Subba Reddy VV. An analysis of concentration of sucrose, endogenous $\mathrm{pH}$, and alteration in the plaque $\mathrm{pH}$ on consumption of commonly used liquid pediatric medicines. J Indian Soc Pedod Prev Dent 2009 Jan-Mar;27(1):44-48.

13. Neves BG, Farah A, Lucas E, de Sousa VP, Maia LC. Are paediatric medicines risk factors for dental caries and dental erosion? Community Dent Health 2010 Mar;27(1):46-51.
14. Tinanoff N, Reisine S. Update on early childhood caries since the Surgeon General's Report. Acad Pediatr 2009 Nov-Dec; 9(6):396-403.

15. Çolak H, Dülgergil CT, Dalli M, Hamidi MM. Early childhood caries update: a review of causes, diagnoses, and treatments. J Nat Sci Biol Med 2013 Jan-Jun;4(1):29-38.

16. Paes Leme AF, Koo H, Bellato CM, Bedi G, Cury JA. The role of sucrose in cariogenic dental biofilm formation - new insight. J Dent Res 2006 Oct;85(10):878-887.

17. Roberts IF, Roberts GJ. Relation between medicines sweetened with sucrose and dental disease. Br Med J 1979 Jul;2(6181): 14-16.

18. Feigal RJ, Gleeson MC, Beckman TM, Greenwood ME. Dental caries related to liquid medication intake in young cardiac patients. ASDC J Dent Child 1984 Sep-Oct;51(5):360-362.

19. Addy, M.; Edgar, WM.; Embeny, G.; Orchardson, R.; editors. Tooth wear and sensitivity: clinical advances in restorative dentistry. London: Informal Healthcare; 2000. p. 129.

20. Feigal RJ, Jensen ME. The cariogenic potential of liquid medications: a concern for the handicapped patient. Spec Care Dentist 1982 Jan-Feb;2(1):20-24.

21. Kenny DJ, Somaya P. Sugar load of oral liquid medications on chronically ill children. J Can Dent Assoc 1989 Jan;55(1):43-46.

22. Pomarico L, Czauski G, Portela MB, de Souza IP, Kneipp L, de Araújo Soares RM, de Araújo Castro GF. Cariogenic and erosive potential of the medication used by HIV-infected children: $\mathrm{PH}$ and sugar concentration. Community Dent Health 2008 Sep;25(3):170-172.

23. Lima KT, Almeida IC, Senna EL. Pediatric medication Sweetener agents and $\mathrm{pH}$. J Bras Odontopediatr Odontol Bebe 2000;3:457-463.

24. Peres KG, Oliveira CT, Peres MA, Raymundo Mdos S, Fett R. Sugar content in liquid oral medicines for children. Rev Saude Publica 2005 Jun;39(3):486-489.

25. Johansson AK, Sorvari R, Birkhed D, Meurman JH. Dental erosion in deciduous teeth - an in vivo and in vitro study. J Dent 2001 Jul;29(5):333-340.

26. Landt $\mathrm{H}$. Oral stereognosis and oral muscular coordination ability. Front Oral Physiol 1983;4:55-79. 